\title{
Case report of novel DYRK1A mutations in 2 individuals with syndromic intellectual disability and a review of the literature
}

\author{
Stephanie M. Luco ${ }^{1}$, Daniela Pohl ${ }^{2}$, Erick Sell ${ }^{2}$, Justin D. Wagner ${ }^{3}$, David A. Dyment ${ }^{1,3^{*}}$ and Hussein Daoud
}

\begin{abstract}
Background: Chromosomal deletions encompassing DYRK1A have been associated with intellectual disability for several years. More recently, point mutations in DYRK1A have been shown to be responsible for a recognizable syndrome characterized by microcephaly, developmental delay and intellectual disability (ID) as well as characteristic facial features. Here we present 2 individuals with novel mutations in DYRK1A, and a review of the cases reported to date.

Case presentation: Both individuals presented with the well-known characteristic features, as well as rarer anomalies seen in a minority of patients. Patient 1 presented shortly after birth with an enlarged cisterna magna, distal contractures, and distinctive facies that included bitemporal narrowing and deep set eyes. A de novo splice site mutation in DYRK1A [c.951 + 4_951 + 7delAGTA; p.Val222Aspfs*22] was identified by next generation sequencing. Patient 2 presented at 7 months of age with microcephaly and dysmorphic features. She went several years without a diagnosis until a de novo DYRK1A nonsense mutation [c.787C $>$ T; p. (Arg263*)] was identified at age 12. These individuals, and the 52 cases reviewed from the literature, show the characteristic features of the DYRK1Arelated syndrome including global developmental delay, ID, microcephaly, feeding difficulties, and the facial gestalt. Other common findings include seizures, vision defects, brain abnormalities and skeletal abnormalities of the hands and feet. Less common features include optic nerve defects, contractures, ataxia, and cardiac anomalies.

Conclusion: DYRK1A testing should be considered in individuals with the facial features, intellectual disability and post-natal microcephaly. Once diagnosed with DYRK1A-related intellectual disability, a cardiac and ophthalmologic assessment would be recommended as would routine surveillance by a pediatrician for psychomotor development, growth, and feeding.
\end{abstract}

Keywords: DYRK1A, Intellectual disability, Microcephaly, Next Generation Sequencing

\section{Background}

The dual-specificity tyrosine phosphorylation-regulated kinase 1A (DYRK1A) (MIM 600855) is located in the Down syndrome critical region of chromosome 21 [1]. It encodes a highly conserved protein that plays an essential role in the development of the central nervous system [2-4]. Haploinsufficiency of DYRK1A is responsible for a syndrome characterized by intellectual disability

\footnotetext{
* Correspondence: ddyment@cheo.on.ca

'Department of Genetics, Children's Hospital of Eastern Ontario, Ottawa, ON K1H 8L1, Canada

${ }^{3}$ Children's Hospital of Eastern Ontario Research Institute, Ottawa K1H 8L1

ON, Canada

Full list of author information is available at the end of the article
}

(ID), microcephaly and dysmorphic features (MIM 614104). Individuals with this condition were initially reported with partial monosomies of chromosome 21 as detected on routine karyotype that encompassed the DYRK1A gene (21q22.13) [5-7]. Since then, numerous cases of chromosome 21 deletions diagnosed by comparative genomic hybridization have been reported by several groups [8-13]. The first intragenic frameshift deletion, identified by direct sequencing, was described by Courcet et al in 2012 [14]. More recently, next generation sequencing (NGS) has led to the diagnosis of numerous de novo mutations in DYRK1A, further characterizing, and broadening, this syndromic phenotype [15-21]. To date, there have been 52 individuals in the 
literature with the DYRK1A-related ID phenotype with both structural rearrangements $(n=19)$ and more recently, single nucleotide variants and small insertions/ deletions within DYRK1A $(n=33)$.

Here, we present 2 additional patients with novel DYRK1A mutations. We also provide a comprehensive review of the previously published cases, further delineating both the common and less commonly seen features of this emerging syndrome.

\section{Case presentations}

Patient 1 was born at $36+3$ weeks, to healthy parents of Iraqi origin. Parents were first cousins once removed. Two older siblings were in good health. There was no family history of ID or congenital anomalies. Intrauterine growth restriction (IUGR) and an enlarged cisterna magna were observed at 35 weeks by routine ultrasound. A prenatal diagnosis of Dandy-Walker malformation was considered but ruled out with post-natal MR imaging (Fig. 1c). Labor was induced given poor fetal growth and the patient was born by vaginal delivery at $36+3$ weeks. At birth, APGAR scores were 6 and 8 at 1 and $5 \mathrm{~min}$. Birthweight was $2.33 \mathrm{~kg}(-2.5 \mathrm{SD})$ and head circumference was $31.5 \mathrm{~cm}(-2.5 \mathrm{SD})$. On examination he had a sacral dimple, increased appendicular tone, and bilateral contractures to the third and fifth digits (Fig. 1d). An echocardiogram showed a patent ductus arteriosus. He experienced feeding difficulties in the neonatal period and required nasogastric feeding.

MRI at 2 weeks of life showed mild prominence of lateral ventricles and extra-axial spaces, enlarged cisterna magna, and a thin corpus callosum. MRI repeated at 10 months of age showed interval enlargement of the supratentorial extra-axial spaces, mild dilatation of the lateral and 3rd ventricles as well as the enlarged cisterna magna and thin corpus callosum (Fig. 1c).

The patient's facial features showed bitemporal narrowing with down-slanted palpebral fissures, deep-set eyes with hooded appearance, a prominent nasal root, low-set and mildly dysplastic ears, and a downturned mouth (Fig. 1a, b). He had bilateral ankle contractures and proximal placement of the first toes. At 4 months of age he continued to have contractures of ankles and 3rd digits of his hands. He is currently followed for visual impairment with bilateral optic atrophy. He has bilateral hydronephrosis. He further has a history of recurring otitis media with resultant conductive hearing loss. From a young age, he has experienced frequent dysphagia and emesis with ingestion of thicker liquids. At 15 months, his weight was $7.9 \mathrm{~kg}(-3.3 \mathrm{SD})$ and length was $72.9 \mathrm{~cm}$ (-2.2 SD). Head circumference showed relatively slower growth velocity at $41.5 \mathrm{~cm}(-4.6 \mathrm{SD})$. At 21 months of age, he had yet to stand or say his first words. A karyotype and microarray were normal. Given the history of

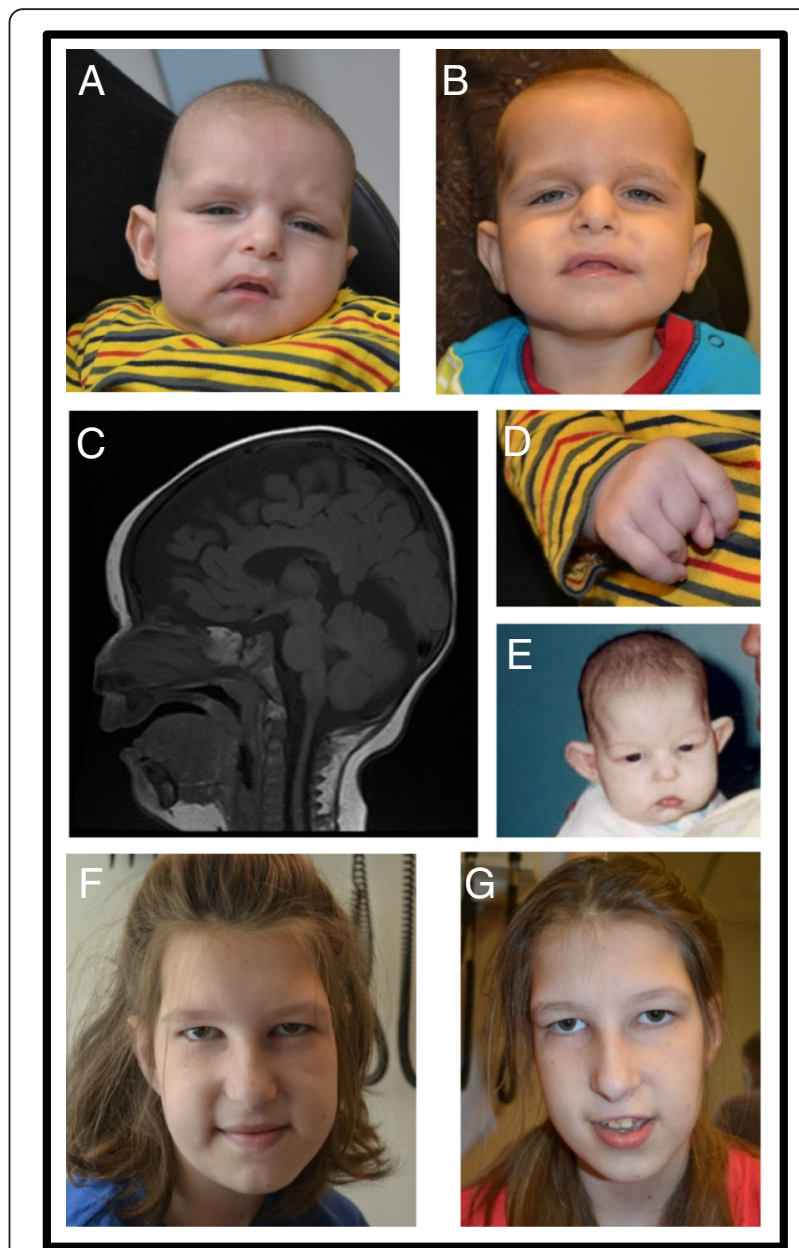

Fig. 1 The characteristic facies of 2 individuals with DYRK1A mutation. a-b Patient 1 with bitemporal narrowing, down-slanted palpebral fissures, deep-set eyes and dysplastic ears. c MR Images in Patient 1 showing thin corpus callosum, enlarged cisterna magna and 4 th ventricle. $\mathbf{d}$ distal contractures seen in Patient 1. e-g Patient 2 with with bitemporal narrowing, deep-set eyes and dysplastic ears

consanguinity and the syndromic features in Patient 1 , the parents of the patient had genetic counselling and were quoted a recurrence risk of up to $25 \%$. The patient was enrolled in a research study at the Children's Hospital of Eastern Ontario, at the age of 13 months.

Patient 2 was born at $41+3$ weeks by spontaneous vaginal delivery, to healthy French Canadian parents. Parents were not consanguineous. The patient has two older siblings in good health. Birthweight was $3.2 \mathrm{~kg}(-1.1 \mathrm{SD})$. There were no concerns in the newborn period with the exception of feeding difficulties. At 7 months of age, she was referred to Genetics for microcephaly and dysmorphic features. At that time she weighed $6.65 \mathrm{Kg}(-1.5 \mathrm{SD})$, with length of $65.2 \mathrm{~cm}(-1 \mathrm{SD})$. Head circumference was 39.8 ( -2.9 SD). On examination, she had bitemporal narrowing, a prominent 
occiput and deep set eyes. In addition, she had a pronounced asymmetry of the ears, with her right ear being lower set, anteverted, and with a simple helix (Fig. 1e-g). She underwent bilateral otoplasty at the age of four.

She experienced several febrile seizures starting at 15 months of age. Her seizures continued in the absence of fever, and she experienced a number of generalized tonic-clonic seizures before beginning anticonvulsant medication at 8 years of age. Her seizures have since been well controlled, with low dose treatment with Levetiracetam. An MRI, at 34 months of age, showed ventricles and subarachnoid space in the upper limits of the normal range but with no other structural abnormality.

She said her first word at 32 months. By 8 years of age she had 10 words, and by 11 years, she occasionally spoke in short sentences. She walked at 25 months. At the age of 12, she was described as having a broad-based clumsy gait, and exhibited a mild tremor and ataxia when reaching for objects. As a toddler, she demonstrated stereotypic behavior including hand flapping, tongue thrusting during feedings, as well as an aversion to being touched and to certain textures. Hand flapping has persisted into adolescence. At 11 years of age, she had a height of $159 \mathrm{~cm}(+2 \mathrm{SD})$, a weight of $56 \mathrm{Kg}(+1.7$ $\mathrm{SD})$, and a head circumference of $51 \mathrm{~cm}(-1.3 \mathrm{SD})$. During her last assessment at age 12, her features were further described as a long face, bitemporal narrowing, hooded palpebral fissures, deep set eyes, prominent nasal bridge and bulbous tip to her nose, smooth philtrum, wide spaced teeth, tapering fingers and mild pectus excavatum (Fig. 1g).

During her diagnostic work-up she underwent several investigations that included normal karyotype, chromosomal microarray, FISH for 22q11.2, methylation specific MLPA and sequencing of $U B E 3 A$, sequencing of MECP1 and MECP2, TCF4, and mitochondrial DNA whole genome sequencing all yielded normal results.

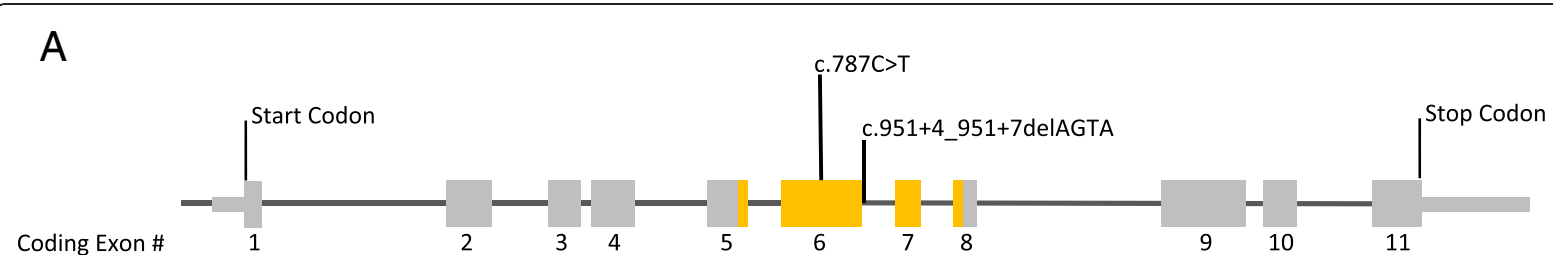

B

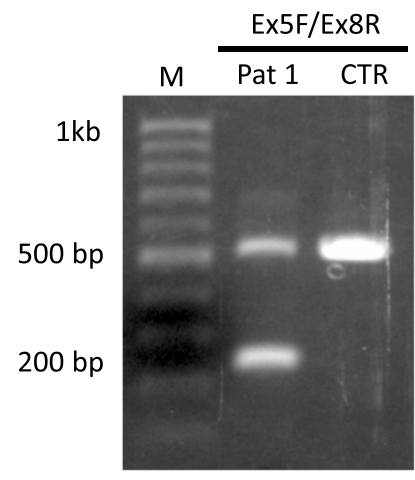

C

WT
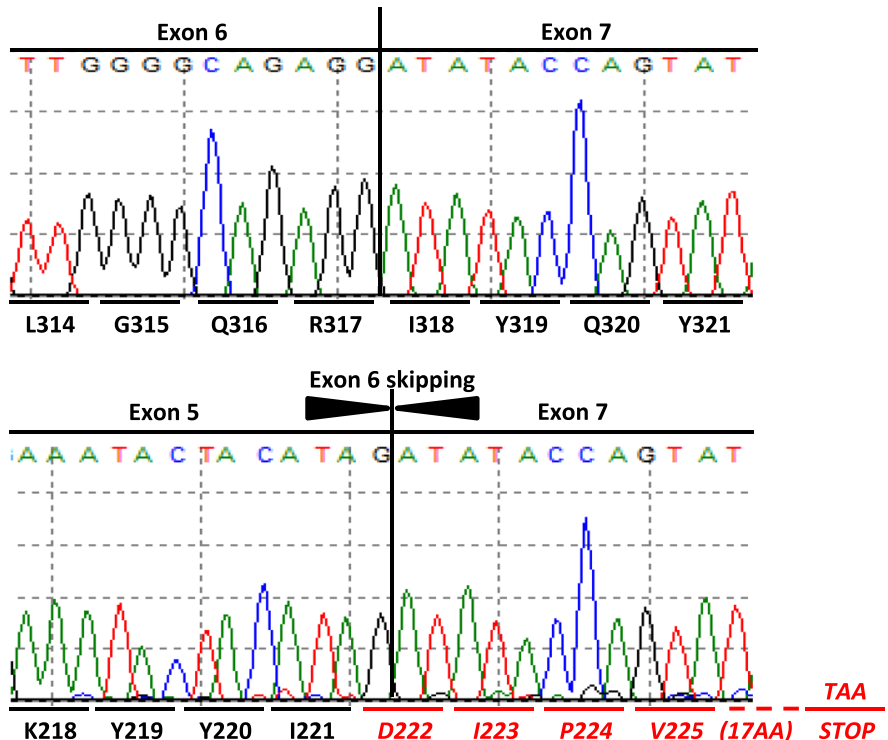

Fig. 2 a Schematic representation of the coding sequence of DYRK1A (NM_001396.3) showing the localization of the two de novo mutations identified in this study. $\mathbf{b}$ Agarose gel electrophoresis of the RT-PCR products from patient 1 (Pat 1) and a control individual (CTR). A fragment covering exons 5-8 was amplified by RT-PCR (yellow in a). The expected 528 bp PCR product was observed from both patient 1 and the control individual, whereas a smaller PCR product ( 240 bp) was only detected in patient 1. A 100 bp ladder was used for reference. c Sequencing of both the wild type (WT) and mutant fragments from patient 1 showing the WT DYRK1A transcript sequence covering exons 6 and 7 , and mutant DYRK1A transcript lacking exon 6, resulting in a frameshift and a premature stop codon 22 codons downstream 


\section{Material and methods}

Genomic DNA was extracted from peripheral blood lymphocytes using standard methods. The Trusight One Sequencing panel (Illumina) was used to capture 4813 genes deemed to be "clinically relevant". Enriched libraries from patient 1 and his parents (trio approach) were pooled and sequenced on the MiSeq (Illumina). The detailed protocol has been previously reported [22]. RT-PCR and Sanger sequencing were performed by standard protocols using primers targeting DYRK1A (NM_001396.3) coding exon-5 (Ex5F:5' TTGAGCTCATGAACAAACATGAC-3') and coding exon-8 (Ex8R:5'-GAGCAGGTGGAATACCCAGA-3') on RNA extracted from patient and control lymphoblast cell lines.

\section{Results and discussion}

A de novo variant in DYRK1A [c.951+4_951+ 7delAGTA; p.Val222Aspfs*22] was identified in patient 1 at 14.5 months of age. This variant is predicted to affect splicing by Alamut Visual version 2.7 (Interactive Biosoftware, Rouen, France) and was confirmed by RT-PCR (Fig. 2b) and Sanger sequencing (Fig. 2c). Patient 2 had clinical testing with a next-generation sequencing panel for epilepsy (Comprehensive Epilepsy Panel; Medical Neurogenetics Lab, Georgia, USA) and this revealed a nonsense mutation [c.787C $>\mathrm{T}$; p.(Arg263*)] in DYRK1A. Parents were tested and found to not carry the mutation in keeping with a de novo mutation.

Both individuals had novel DYRK1A mutations, and presented with the key features of the DYRK1A phenotype, as well as less commonly observed findings that contribute to a broadening of the phenotypic spectrum of this recognizable syndrome. Patient 1 was seen prenatally given the IUGR and an enlarged cisterna magna observed on routine prenatal ultrasound. At birth, camptodactyly, hypertonia, and distinctive facial features were noted. A diagnosis occurred at 14.5 months of age and was possible because of the early recognition of a likely monogenic syndrome and accessibility to comprehensive, NGS-based panel testing. In contrast, Patient 2 was referred to Genetics given the history of a mild postnatal microcephaly, dysmorphic features and developmental delays. During her childhood she experienced an extensive diagnostic odyssey with many genetic, metabolic, and imaging investigations performed. A molecular diagnosis was also possible with NGS panel testing for epilepsy-related genes at age 12 years.

A PubMed search for reported cases of DYRK1A mutations or partial chromosome 21 deletions yielded a total of 52 patients from 17 papers (Table 1). A summary of the clinical features of the 2 patients and the previously published cases is shown in Table 2 . We recognize that any conclusions based on published data may enrich
Table 1 DYRK1A mutations reported in the literature

\begin{tabular}{|c|c|c|}
\hline Paper & $\begin{array}{l}\text { \# of } \\
\text { patients }\end{array}$ & Types of mutations \\
\hline $\begin{array}{l}\text { Bartsch et al } \\
1997[7]\end{array}$ & 1 & Translocation \\
\hline $\begin{array}{l}\text { Matsumoto et al } \\
1997[6]\end{array}$ & 1 & Deletion \\
\hline $\begin{array}{l}\text { Møller et al } \\
2008[8]\end{array}$ & 2 & 2 translocations \\
\hline $\begin{array}{l}\text { Fujita et al } \\
2010[9]\end{array}$ & 1 & Deletion \\
\hline $\begin{array}{l}\text { Oegema et al } \\
2010[10]\end{array}$ & 2 & 2 deletions \\
\hline $\begin{array}{l}\text { Yamamoto et al } \\
2011[11]\end{array}$ & 3 & 3 deletions \\
\hline $\begin{array}{l}\text { van Bon et al } \\
2011[12]\end{array}$ & 1 & Deletion \\
\hline $\begin{array}{l}\text { Valetto et al } \\
2012[13]\end{array}$ & 1 & Deletion \\
\hline $\begin{array}{l}\text { Courcet et al } 2012 \\
\text { [14] }\end{array}$ & 2 & 1 deletion, 1 frameshift \\
\hline $\begin{array}{l}\text { O'Roak et al } \\
2012[15]\end{array}$ & 3 & 2 frameshifts, 1 splice site \\
\hline $\begin{array}{l}\text { Okamoto et al } 2015 \\
\text { [27] }\end{array}$ & 1 & Nonsense \\
\hline $\begin{array}{l}\text { Redin et al } \\
2014 \text { [16] }\end{array}$ & 2 & 1 nonsense, 1 frameshift \\
\hline $\begin{array}{l}\text { Iglesias et al } \\
2014[17]\end{array}$ & 1 & Nonsense \\
\hline $\begin{array}{l}\text { Ruaud et al } \\
2015 \text { [19] }\end{array}$ & 2 & 1 nonsense, 1 missense \\
\hline $\begin{array}{l}\text { van Bon et al } 2015 \\
{[18]}\end{array}$ & 5 & 2 nonsense, 3 splice site \\
\hline $\begin{array}{l}\text { Bronicki et al } \\
2015[20]\end{array}$ & 10 & $\begin{array}{l}3 \text { nonsense, } 2 \text { missense, } 4 \text { frameshift, } \\
1 \text { deletion }\end{array}$ \\
\hline Ji et al 2015 [21] & 14 & $\begin{array}{l}3 \text { nonsense, } 3 \text { missense, } 3 \text { frameshift, } \\
5 \text { deletions }\end{array}$ \\
\hline
\end{tabular}

for more severe phenotypes; however the relatively large number of cases $(n=54)$ may attenuate this potential source of bias. The age at diagnosis of the patients and those from the literature showed a wide range from 17 months to 59 years. The 14.5 months observed for patient 1 was the earliest reported molecular diagnosis. On history, disease manifestations were early in most patients and prenatal findings were observed in 33/43 (77\%). This included 21 cases of IUGR, 2 cases of oligohydramnios and 1 case of polyhydramnios. Birth measurements were commonly in the low range $(<-2 \mathrm{SD})$, though this was not universal. In aggregate, the most common features were ID and developmental delay seen in 53/53 cases (100\%), dysmorphic facies in 53/54 (98\%), feeding difficulties in 44/46 (96\%), and microcephaly (<-2 SD) seen in 44/51 (86\%). A number of other features were also noted in the majority such as 
Table 2 Summary of the clinical presentation of patients with DYRK1A mutations

\begin{tabular}{|c|c|c|c|c|c|}
\hline & Patient 1 & Patient 2 & $\begin{array}{l}\text { SNV, Splice, FS } \\
\text { (33) }\end{array}$ & $\begin{array}{l}\text { Rearrangements } \\
\text { (19) }\end{array}$ & $\begin{array}{l}\text { Total } \\
(54)\end{array}$ \\
\hline $\begin{array}{l}\text { Age at last reported } \\
\text { assessment }\end{array}$ & 22 months & 13 years & $\begin{array}{l}21 \text { month - } \\
59 \text { years }\end{array}$ & $\begin{array}{l}17 \text { months - } \\
33 \text { years }\end{array}$ & \\
\hline IUGR / prenatal findings & $\begin{array}{l}\text { IUGR, enlarged } \\
\text { cisterna magna }\end{array}$ & - & $17 / 26$ & $15 / 16$ & $33 / 43$ \\
\hline $\begin{array}{l}\text { Head circumference } \\
\text { at birth }(<-2 \text { SD) }\end{array}$ & $-2.5 \mathrm{SD}$ & & $13 / 22$ & $15 / 16$ & $29 / 39$ \\
\hline Low birth weight (<-2 SD) & $-2.5 \mathrm{SD}$ & - & $13 / 27$ & $14 / 19$ & $28 / 47$ \\
\hline Length at birth $(<-2 \mathrm{SD})$ & - & - & $12 / 21$ & $12 / 15$ & $24 / 36$ \\
\hline Feeding difficulties & + & + & $28 / 30$ & $14 / 14$ & $44 / 46$ \\
\hline Microcephaly $(<-2$ SD) & $-4.6 \mathrm{SD}$ & $-1.3 \mathrm{SD}$ & $26 / 31$ & $17 / 18$ & $44 / 51$ \\
\hline Weight (<-2 SD) & $-3.3 \mathrm{SD}$ & $+1.7 \mathrm{SD}$ & $7 / 26$ & $12 / 17$ & $20 / 45$ \\
\hline Height (<-2 SD) & $-2.2 \mathrm{SD}$ & $+2 \mathrm{SD}$ & $7 / 28$ & $12 / 18$ & $20 / 48$ \\
\hline Global developmental delay & + & + & $33 / 33$ & $18 / 18$ & $53 / 53$ \\
\hline Intellectual disability & & + & $31 / 32$ & $19 / 19$ & $51 / 52$ \\
\hline Speech delay / absence & + & + & $32 / 32$ & $17 / 17$ & $51 / 51$ \\
\hline Motor delay / late walking & + & + & $22 / 22$ & $11 / 12$ & $35 / 36$ \\
\hline Abnormal gait & & + & $18 / 20$ & $7 / 9$ & $26 / 30$ \\
\hline Behavioral issues & - & + & $29 / 31$ & $9 / 11$ & $39 / 44$ \\
\hline Stereotypies & - & + & $20 / 25$ & $6 / 9$ & $27 / 36$ \\
\hline Autism spectrum disorder & & - & $14 / 27$ & $2 / 7$ & $16 / 35$ \\
\hline Anxiety & - & + & $9 / 18$ & $1 / 5$ & $11 / 24$ \\
\hline Hyperactivity / ADHD & - & - & $5 / 21$ & $3 / 7$ & $8 / 30$ \\
\hline Febrile seizures & - & + & $17 / 29$ & $13 / 15$ & $31 / 46$ \\
\hline Seizures / epilepsy & - & + & $14 / 28$ & $13 / 17$ & $28 / 47$ \\
\hline Brain abnormalities (MRI) & + & Normal & $18 / 24$ & $13 / 16$ & $32 / 42$ \\
\hline Enlarged ventricles & + & & 10 & 4 & $22^{a}$ \\
\hline General / cortical atrophy & + & & 8 & 6 & $17^{\mathrm{a}}$ \\
\hline Thin brainstem & - & & 2 & 2 & $13^{\mathrm{a}}$ \\
\hline $\begin{array}{l}\text { Hypoplastic corpus } \\
\text { callosum }\end{array}$ & - & & 2 & 4 & $9^{a}$ \\
\hline $\begin{array}{l}\text { Optic disk/nerve } \\
\text { anomaly }\end{array}$ & Optic disc pallor & - & 5 & 1 & 7 \\
\hline Vision abnormalities & Visual impairment & - & $16 / 21$ & $8 / 9$ & $25 / 32$ \\
\hline Dysmorphic facies & + & + & $32 / 33$ & $19 / 19$ & $53 / 54$ \\
\hline $\begin{array}{l}\text { Abnormalities of the } \\
\text { hands or feet }\end{array}$ & $\begin{array}{l}\text { Small feet, toe brachydactyly, } \\
\text { proximal placement of first toes }\end{array}$ & $\begin{array}{l}\text { Tapering fingers, high arched } \\
\text { feet }\end{array}$ & $15 / 16$ & $8 / 10$ & $25 / 28$ \\
\hline $\begin{array}{l}\text { Abnormalities of the } \\
\text { spine or chest }\end{array}$ & - & Mild pectus excavatum & $6 / 8$ & $4 / 7$ & $11 / 17$ \\
\hline Contractures & $\begin{array}{l}\text { Bilateral: third and fifth digits, } \\
\text { ankles }\end{array}$ & - & $3 /-$ & $1 /-$ & $5 /-$ \\
\hline $\begin{array}{l}\text { Gastrointestinal } \\
\text { symptoms }\end{array}$ & GERD, vomiting & - & $13 /-$ & $3 /-$ & $17 /-$ \\
\hline
\end{tabular}


Table 2 Summary of the clinical presentation of patients with DYRK1A mutations (Continued)

\begin{tabular}{lllll}
\hline Genitourinary & Bilateral hydronephrosis & - & $5 /-$ & $3 /-$ \\
Cardiac & PDA & - & $2 /-$ & $5 /-$ \\
Recurrent infections & + & - & $7 /-$ & $3 /-$ \\
\hline
\end{tabular}

SNV single nucleotide variant, FS frameshift, mo Months, yrs Years, IUGR intrauterine growth restriction, $S D$ standard deviation, $A D H D$ attention deficit hyperactivity disorder, MRI magnetic resonance imaging, GERD gastroesophageal reflux disease, PDA patent ductus arteriosus

${ }^{a}$ One paper (Ji et al [21]) did not assign the type of abnormalities to each patient, but gave a total prevalence for their cohort. These values have been added to our total, but were not included in the group subtotals

stereotypies and abnormal gait (Table 2). Weight and height at last clinical assessment were less than -2 SD in only 44 and $42 \%$ respectively. There were 5 patients who were within the normal range for height, weight and head circumference.

Febrile seizures were reported in 31/46 (67 \%) cases and a later diagnosis of epilepsy or non-febrile seizures was observed in $60 \%$. Patient 2 and 8 other patients from the literature were reported to have good control of their seizures with anti-epileptic medication. Two children from the literature were described as having progressively worsening seizures, one presented with seizures shortly after birth and the other was refractory to medication by the age 10 years $[11,13]$. Both patients had large deletions encompassing DYRK1A in addition to other genes on chromosome 21.

Results of brain imaging were reported for 42 patients from the literature. Thirty-two had abnormal findings (76 \%). Enlarged ventricles were described in 22 patients, general or cortical atrophy in 17 patients, a thin brainstem in 13 patients, and a thin corpus callosum in 9 patients. Other less common findings include pituitary stalk hypoplasia in 7 cases, a neuronal migration defect in 1 case, and an enlarged cisterna magna observed in our case (Fig. 1c). An additional less commonly seen feature observed in Patient 1 was bilateral optic disc pallor. Anomalies of the optic disc or optic nerve have been seen in 6 other individuals with DYRK1A mutations. Visual abnormalities were seen in 25 of 32 patients, including hyperopia, myopia, strabismus, astigmatism, exotropia, amblyopia, and corneal clouding. There was also retinal detachment in the oldest individual published in the literature, at 59 years.

Dysmorphic features characteristic of a DYRK1A mutation were near universal in 53/54 patients. This includes deep set eyes with a hooded appearance to the lateral aspect of the palpebral fissures, a prominent nasal root, bitemporal narrowing, prominent and dysplastic ears. Hand and/or foot abnormalities were also seen in 25 patients that included long tapered fingers, small hands and feet, 5th finger clinodactyly, toe syndactyly, high arched feet, and proximal placement of the first toe. Polydactyly was reported in 2 cases. Spinal or thoracic abnormalities were seen in 11 patients; presenting with pectus excavatum, kyphosis, scoliosis, and abnormal cervical spine. Seventeen patients were reported to have gastrointestinal symptoms, including gastroesophageal reflux disease in 12 patients, 3 of whom required a Nissen fundoplication, recurrent vomiting in 4 patients, pyloric stenosis in 2 patients, and duodenal atresia in 1 patient.

Our summary of the previously reported cases and our 2 cases highlight relatively rare findings within this group. Contractures in the digits or lower limbs were seen in our patient 1 (Fig. 1d) as well as 4 others. An ataxic gait, seen in patient 2, was also described in 5 other individuals. There have been 10 cases in the literature that reported recurring or frequent infections. Cardiac anomalies, including ventricular septal defect (VSD), patent ductus arteriosis (PDA), and aortic valve stenosis or insufficiency, were found in 8 cases. There were 9 reports of genitourinary findings: cryptorchidism in 3 patients, unilateral renal agenesis, pelvic kidney, renal cyst, hypospadia, micropenis, and our patient 1 with bilateral hydronephrosis. Though these cardiac and renal findings are not seen in the majority of patients with DYRK1A mutations, they should be considered during monitoring and long-term care.

A schematic representation of the 35 intragenic and de novo DYRK1A mutations is shown in Fig. 3. The DYRK1A protein contains a kinase domain, spanning from residue 158 - 479 [23]. Other important features in the $\mathrm{N}$-terminus include a nuclear localization signal and a DYRK-homology box, a sequence highly conserved in the DYRK family of unknown function [23, 24]. From residue 588 to 616 , there is a targeting signal that has been shown to cause localization of the protein to subnuclear compartments associated with splicing machinery [25]. The majority of mutations occurred within the kinase domain or in the N-terminal (12 nonsense, 10 frameshift, and 5 splice site mutations). Of the 6 missense mutations, 5 occurred within the kinase domain, potentially leading to diminished protein function. The only missense mutation falling outside of the functional domain alters the first residue of the speckletargeting signal, important for the localization of the DYRK1A protein. There does not seem to be a clear genotype-phenotype correlation with the mutations and the phenotypes reported. There were 4 patients with the same nonsense mutation, p.Arg205* reported by 


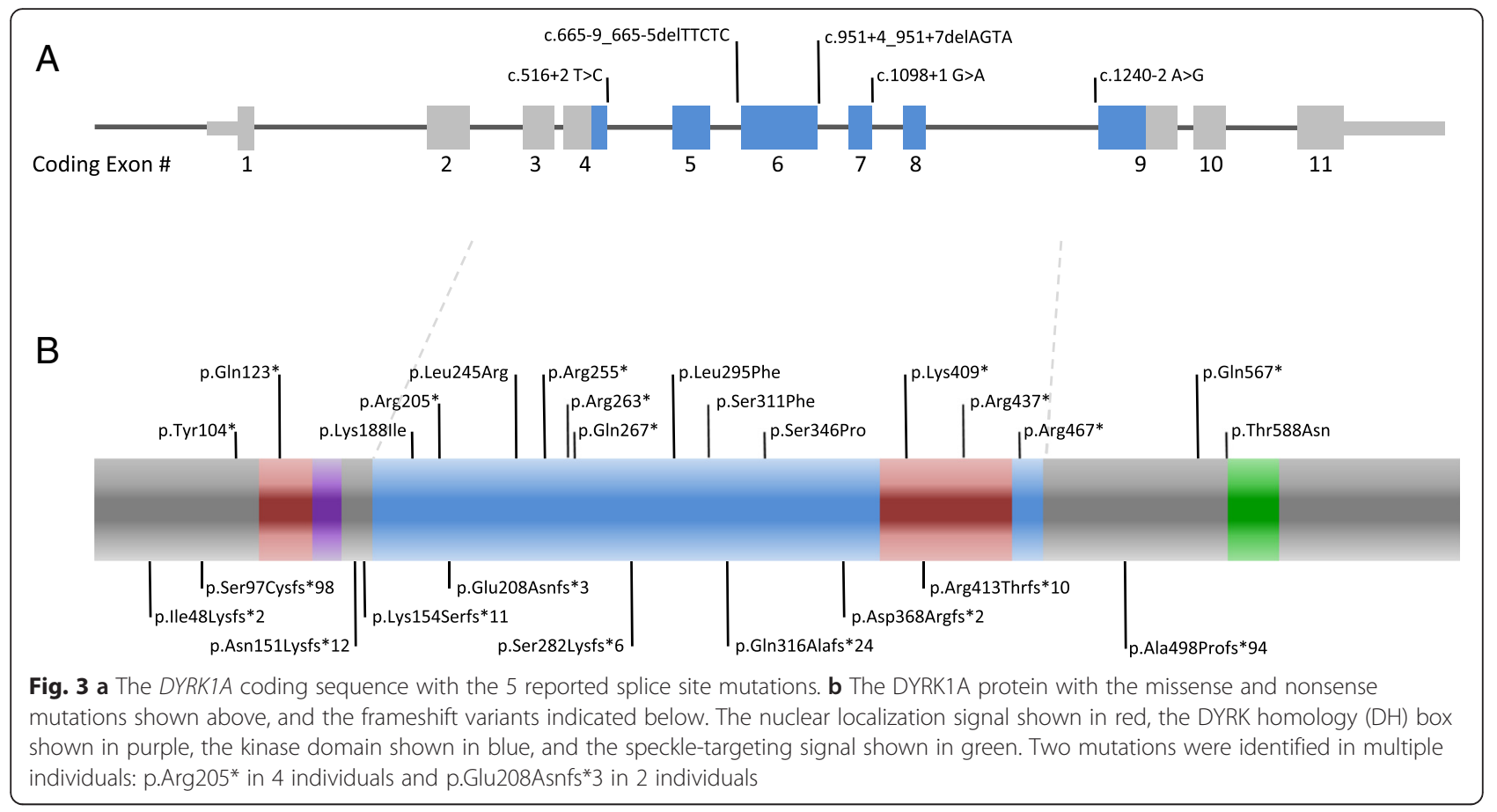

different groups and they did not appear to differ from the majority of cases reported. The recurrence of the p.Arg205* mutation is likely due to its location in a CpG dinucleotide, which are mutation hotspots [26].

\section{Conclusion}

In summary, children with ID and syndromic features should be considered for a possible DYRK1A mutation testing especially if the recognizable facial features are present. Growth and feeding issues would also support its potential diagnosis. At the time of diagnosis, abdominal ultrasound, cardiac and ophthalmological assessments would be recommended given the frequency of anomalies. Genetic counselling would also be recommended in view of the potential for a balanced translocation in a parent with a child carrying microdeletions encompassing DYRK1A [7, 21]. A recurrence due to possible gonadal mosaicism has yet to be observed. Routine follow-up with a pediatrician would be highly recommended given feeding issues, growth and developmental delays.

\section{Consent}

Written and informed consent was obtained from the parents of the patients for the publication of this manuscript and the accompanying images of the patients. A copy of the patient consents for publication of images are available to the Editor of this journal.

The individuals in the study were recruited by physician referral. The study was conducted in accordance with the Declaration of Helsinki protocols and approved by the regional ethics review board at the Children's Hospital of Eastern Ontario, Ottawa, ON (Protocol Number 08/71X). Written and informed consent for the molecular studies were obtained and available for review by the Editor of the journal.

\section{Abbreviations}

DYRK1A: dual-specificity tyrosine phosphorylation-regulated kinase $1 \mathrm{~A}$; ID: intellectual disability; IUGR: intrauterine growth restriction; SD: standard deviation; MR imaging: MRI, Magnetic resonance imaging;

DNA: deoxyribonucleic acid; RT-PCR: reverse transcriptase polymerase chain reaction; FISH: fluourescence in situ hybridization; MLPA: multiplex ligationdependent probe amplification; NGS: next generation sequencing; GERD: gastroesophageal reflux disease; VSD: ventricular septal defect; PDA: patent ductus arteriosus.

\section{Competing interests}

The authors declare that they have no competing interests.

\section{Authors' contributions}

SML performed and analyzed the data from literature review and wrote the manuscript. DP and ES provided the clinical information for the case reports and made a substantive contribution to the writing and editing of the manuscript. JDW performed and interpreted the laboratory experiments and contributed to the writing and editing of the draft manuscript. DAD and HD conceived the study design, interpreted the exome and clinical data and cowrote and edited the manuscript. All authors read and approved the manuscript.

\section{Acknowledgements}

The authors would like to thank the patients and their families, without their participation this work would not have been possible. The authors would like to acknowledge Wen Qin and Wendy Mears for their technical assistance. This work was performed under a grant from the Children's Hospital of Eastern Academic Health Science Centres (AHSC) AFP Innovation Fund. DAD is supported by the CIHR Institute of Genetics Clinical Investigatorship Award. SML is supported of a CIHR Health Professional Student Research Award. The authors would also like to thank the Care 4 Rare Consortium and Dr. Kym Boycott for helpful assistance in all aspects of this work. 


\section{Author details}

'Department of Genetics, Children's Hospital of Eastern Ontario, Ottawa, ON K1H 8L1, Canada. ²Division of Pediatric Neurology, Children's Hospital of Eastern Ontario, Ottawa K1H 8L1 ON, Canada. ${ }^{3}$ Children's Hospital of Eastern Ontario Research Institute, Ottawa K1H 8L1 ON, Canada.

Received: 12 August 2015 Accepted: 8 February 2016

Published online: 27 February 2016

\section{References}

1. Guimera J, Casas C, Pucharcos C, Solans A, Domenech A, Planas AM, et al. A human homologue of Drosophila minibrain (MNB) is expressed in the neuronal regions affected in Down syndrome and maps to the critical region. Hum Mol Genet. 1996;5(9):1305-10.

2. Hämmerle B, Vera-Samper E, Speicher S, Arencibia R, Martınez S, Tejedor F. Mnb/Dyrk1A is transiently expressed and asymmetrically segregated in neural progenitor cells at the transition to neurogenic divisions. Dev Biol. 2002:246(2):259-73.

3. Martinez de Lagran M, Benavides-Piccione R, Ballesteros-Yanez I, Calvo M, Morales M, Fillat C, et al. Dyrk1A influences neuronal morphogenesis through regulation of cytoskeletal dynamics in mammalian cortical neurons. Cereb Cortex. 2012;22(12):2867-77.

4. Soppa U, Schumacher J, Florencio Ortiz V, Pasqualon T, Tejedor F, Becker W. The Down syndrome-related protein kinase DYRK1A phosphorylates p27Kip1 and Cyclin D1 and induces cell cycle exit and neuronal differentiation. Cell Cycle. 2014;13(13):2084-100.

5. Chettouh Z, Croquette MF, Delobel B, Gilgenkrants S, Leonard C, Maunoury C, et al. Molecular mapping of 21 features associated with partial monosomy 21: involvement of the APP-SOD1 region. Am J Hum Genet. 1995;57(1):62-71.

6. Matsumoto N, Ohashi H, Tsukahara M, Kim KC, Soeda E, Niikawa N. Possible narrowed assignment of the loci of monosomy 21-associated microcephaly and intrauterine growth retardation to a 1.2-Mb segment at 21q22.2. Am J Hum Genet. 1997;60(4):997-9.

7. Bartsch O, Hinkel GK, Petersen MB, König U, Bugge M, Mikkelsen M, et al. A large family with subtelomeric translocation t $(18 ; 21)(q 23 ;$ q22. 1) and molecular breakpoint in the Down syndrome critical region. Hum Genet. 1997;100(5-6):669-75.

8. Møller RS, Kübart S, Hoeltzenbein M, Heye B, Vogel I, Hansen CP, et al. Truncation of the Down syndrome candidate gene DYRK1A in two unrelated patients with microcephaly. Am J Hum Genet. 2008;82(5):1165-70.

9. Fujita H, Torii C, Kosaki R, Yamaguchi S, Kudoh J, Hayashi K, et al. Microdeletion of the Down syndrome critical region at 21q22. Am J Med Genet A. 2010;152(4):950-3.

10. Oegema R, de Klein A, Verkerk AJ, Schot R, Dumee B, Douben H, et al. Distinctive Phenotypic Abnormalities Associated with Submicroscopic 21q22 Deletion Including DYRK1A. Mol Syndromol. 2010;1(3):113-20.

11. Yamamoto T, Shimojima K, Nishizawa T, Matsuo M, Ito M, Imai K. Clinical manifestations of the deletion of Down syndrome critical region including DYRK1A and KCNJ6. Am J Med Genet A. 2011;155(1):113-9.

12. Van Bon B, Hoischen A, Hehir-Kwa J, de Brouwer A, Ruivenkamp C, Gijsbers $A$, et al. Intragenic deletion in DYRK1A leads to mental retardation and primary microcephaly. Clin Genet. 2011;79(3):296-9.

13. Valetto A, Orsini A, Bertini V, Toschi B, Bonuccelli A, Simi F, et al. Molecular cytogenetic characterization of an interstitial deletion of chromosome 21 (21q22. 13q22. 3) in a patient with dysmorphic features, intellectual disability and severe generalized epilepsy. Eur J Med Genet. 2012;55(5): 362-6.

14. Courcet JB, Faivre L, Malzac P, Masurel-Paulet A, Lopez E, Callier P, et al. The DYRK1A gene is a cause of syndromic intellectual disability with severe microcephaly and epilepsy. J Med Genet. 2012;49(12):731-6.

15. O'Roak BJ, Vives L, Fu W, Egertson JD, Stanaway IB, Phelps IG, et al. Multiplex targeted sequencing identifies recurrently mutated genes in autism spectrum disorders. Science. 2012;338(6114):1619-22.

16. Redin C, Gerard B, Lauer J, Herenger Y, Muller J, Quartier A, et al. Efficient strategy for the molecular diagnosis of intellectual disability using targeted high-throughput sequencing. J Med Genet. 2014;51(11):724-36.

17. Iglesias A, Anyane-Yeboa K, Wynn J, Wilson A, Cho MT, Guzman E, et al. The usefulness of whole-exome sequencing in routine clinical practice. Genet Med. 2014;16:922-31.
18. Van Bon B, Coe B, Bernier R, Green C, Gerdts J, Witherspoon K, Kleefstra T, Willemsen M, Kumar R, Bosco P. Disruptive de novo mutations of DYRK1A lead to a syndromic form of autism and ID. Mol Psychiatry. 2016;21(1):126-32.

19. Ruaud L, Mignot C, Guët A, Ohl C, Nava C, Héron D, et al. DYRK1A mutations in two unrelated patients. Eur J Med Genet. 2015;58(3):168-74.

20. Bronicki LM, Redin C, Drunat S, Piton A, Lyons M, Passemard S, Baumann C, Faivre L, Thevenon J, Rivière J. Ten new cases further delineate the syndromic intellectual disability phenotype caused by mutations in DYRK1A. Eur J Med Genet. 2015;23(11):1482-7.

21. Ji J, Lee H, Argiropoulos B, Dorrani N, Mann J, Martinez-Agosto JA, GomezOspina N, Gallant N, Bernstein JA, Hudgins L. DYRK1A haploinsufficiency causes a new recognizable syndrome with microcephaly, intellectual disability, speech impairment, and distinct facies. Eur J Med Genet. 2015; 23(11):1473-81.

22. Richer J, Daoud H, Geier P, Jarinova O, Carson N, Feberova J, et al. Resolution of refractory hypotension and anuria in a premature newborn with loss-of-function of ACE. Am J Med Genet A. 2015;167(7):1654-8.

23. Soundararajan M, Roos AK, Savitsky P, Filippakopoulos P, Kettenbach AN, Olsen JV, et al. Structures of Down syndrome kinases, DYRKs, reveal mechanisms of kinase activation and substrate recognition. Structure. 2013; 21(6):986-96.

24. Becker W, Joost $\mathrm{H}$. Structural and functional characteristics of Dyrk, a novel subfamily of protein kinases with dual specificity. Prog Nucleic Acid Res Mol Biol. 1998:62:1-17.

25. Alvarez M, Estivill X, de la Luna S. DYRK1A accumulates in splicing speckles through a novel targeting signal and induces speckle disassembly. J Cell Sci. 2003;116(Pt 15):3099-107.

26. Kong A, Frigge ML, Masson G, Besenbacher S, Sulem P, Magnusson G, Gudjonsson SA, Sigurdsson A, Jonasdottir A, Jonasdottir A, Wong WS, Sigurdsson G, Walters GB, Steinberg S, Helgason H, Thorleifsson G, Gudbjartsson DF, Helgason A, Magnusson OT, Thorsteinsdottir U, Stefansson K. Rate of de novo mutations and the importance of father's age to disease risk. Nature. 2012:488(7412):471-5.

27. Okamoto N, Miya F, Tsunoda T, Kato M, Saitoh S, Yamasaki M, Shimizu A, Torii C, Kanemura Y, Kosaki K. Targeted next-generation sequencing in the diagnosis of neurodevelopmental disorders. Clin Genet. 2015;88(3):288-92.

\section{Submit your next manuscript to BioMed Central and we will help you at every step:}

- We accept pre-submission inquiries

- Our selector tool helps you to find the most relevant journal

- We provide round the clock customer support

- Convenient online submission

- Thorough peer review

- Inclusion in PubMed and all major indexing services

- Maximum visibility for your research

Submit your manuscript at www.biomedcentral.com/submit
) Biomed Central 